\title{
Assessment of Rational Antibiotic Prescribing in Public Hospitals in Nasarawa State, Nigeria
}

\author{
Yakubu Boyi Ngwai, Istifanus Haruna Nkene, Rejoice Helma Abimiku and Sabiu Adamu
}

\begin{abstract}
Antibiotics are the most commonly used medicines in healthcare facilities globally; and they are often misused, especially in developing countries. Periodic assessment of antibiotic prescribing practices is essential to improve prescribing standards and ensure rational use. A cross-sectional, retrospective evaluation of antibiotic prescribing in public secondary and tertiary hospitals in Nasarawa State, Nigeria was carried out. A total of 2800 case sheets of patients who accessed the hospitals under review during the period 2008-2018 were randomly sampled and evaluated. Prescribing indicators of World Health Organization (WHO) and Strengthening Pharmaceutical System/United States Agency for International Development (SPS/USAID) were evaluated and compared with published standards for each of the indicators to identify irrational antibiotic use. Percentage of hospitalization with one or more antimicrobials prescribed was $75.6 \%$. Average number of antimicrobials prescribed per hospitalization in which antibiotics were used was $1.75 \pm 0.66$. Percentage of antibiotic prescribed consistent with hospital formulary was $100.0 \%$. Average duration of prescribed antimicrobial treatment was $5.57 \pm 2.42$ days. Percentage of antimicrobials prescribed by generic name was 45.8\% . Percentage of injectable antibiotic used was $36.4 \%$. Percentage of antimicrobials prescribed from the national essential medicine list was $85.7 \%$. Average encounter with antibiotic was $0.82 \pm 0.2$. Many of the prescribing indicators deviated from the WHO or SPS/USAID optimal values; and thus, were predictors of irrational antibiotic prescribing. Continuous education and re-training of prescribers in public hospitals in Nasarawa State to comply with approved standards of prescribing should be emphasized in to ensure rational antibiotic use.
\end{abstract}

Keywords: Antibiotic; periodic assessment; public hospitals; rational antibiotics.
Published Online: July 16,2020

ISSN: 2684-5199

DOI :10.24018/ejbio.2020.1.4.31

\section{Y. B. Ngwai*}

Nasarawa State University Keffi, Nigeria. (e-mail: ngwaiyb@yahoo.com) I. H. Nkene

Nasarawa State University Keffi, Nigeria. (e-mail: nkeneharuna@gmail.com)

R. H. Abimiku

Plateau State Human Virology Research Centre (PLASVIREC) Jos, Nigeria.

(e-mail: rejoiceafrica40@gmail.com)

S. Adamu

Federal Medical Centre Keffi, Nigeria.

(e-mail: sabiudm ${ }^{\circledR}$ gmail.com)

*Corresponding Author

\section{INTRODUCTION}

Medicines play a vital role in healthcare delivery as drug therapy has remained the most commonly used method to manage diseases in medical practice, leading to reduction in mortality, disease burden and quality of life [1]. Seventy-four (74\%) of hospital out-patient visits involve the administration of medicines [2]. Consequently, there is critical need for appropriate/rational use of medicines to ensure appropriate medical care to patients and the quality of health outcomes [3]. However, their use is often inappropriate, making the need to register the patterns of drug use essential to improve prescribing standards [2], [4]. According to the World Health Organization, over $50 \%$ of medicines prescribed, administered or vended globally are done inappropriately [5].

Rational drug use refers to the prescription of the right drug, for the right patient (indication), at the right dosage and dosing frequency, for the right duration and at the right (lowest) cost to the patients and their community [6], [7], [8]. In view of this, the use of medicines that do not meet the needs of patients in terms of disease condition, dose, frequency and duration of therapy is described as inappropriate (irrational) use of medicines [9]. Rational use of drugs has become an indicator for measuring quality of healthcare [10], [11].

Antibiotics are a type of antimicrobial drug used to treat and prevent bacterial infection by either by killing or inhibiting the growth of bacteria [12]. Antibiotics are the most prescribed drugs worldwide in hospital settings; and play a vital role in combating bacterial infection and maintaining the health of individuals especially in developing countries [13].

The World Health Organization has defined rational use of antibiotics as 'the cost-effective use of antibiotics which maximizes clinical therapeutic effect while minimizing both drug-related toxicity and the development of antimicrobial resistance (AMR)' [14]. The rational (prudent) use of antibiotics will reduce healthcare costs and potential adverse effects to the individual taking them and also diminishes the wide ecologic effects leading to selection of antibiotic resistant bacteria [15]. The most effective strategy for combating antibiotic resistance is rational antibiotic prescription [16].

The critical step to limit the irrational use of medicines is to quantify the extent to which irrational use is occurring. The WHO, in collaboration with the International Network of 
Rational Use of Drugs (INRUD), developed a set of indicators to measure the performance of healthcare facilities related to the utilization of drugs. Although the drug use indicators were originally created to measure drug use in outpatient settings in primary level facilities [14], their use has been extended to in-patients settings of tertiary hospitals [12], [17], [18], [19],[20], [21], [22],[23], [24]. Specifically, the WHO prescribing indicators are the average number of medicines prescribed per patient encounter, percentage of medicines prescribed by generic name, percentage of patient encounters with an antibiotic prescribed, percentage of patient encounters with prescribed injection and the percentage of medicines prescribed from the National essential medicines list (NEML) [15]. Apart from the WHO/INRUD drug use indicators, the USAID-funded Strengthening Pharmaceutical Systems Program developed 17 Antimicrobial Use Indicators - 5 (Indicator 1-5) are hospital-related, 9 (Indicator 6-14) are prescribing indicators, 2 (Indicator 15-16) are patient care indicators and 1 (Indicator 17) is a supplemental indicator [25]. The prescribing indicators are: Indicator 6 (Percentage of hospitalizations with one or more antimicrobials prescribed); Indicator 7 (Average number of antimicrobials prescribed per hospitalization in which antimicrobials were prescribed); Indicator 8 (Percentage of antimicrobials prescribed consistent with the hospital formulary list, which may or may not be part of national essential medicine list or formulary); Indicator 9 (Average cost of antimicrobials prescribed per hospitalization in which antimicrobials were prescribed); Indicator 10 (Average duration of prescribed antimicrobial treatment); Indicator 11 (Percentage of patients who receive surgical antimicrobial prophylaxis for cesarean section in accordance with hospital guideline); Indicator 12 (Average number of doses of surgical antimicrobial prophylaxis prescribed for cesarean section procedures); Indicator 13 (Percentage of patients with pneumonia who are prescribed antimicrobials in accordance with standard treatment guidelines); and Indicator 14 (Percentage of antimicrobials prescribed by generic name).

The extent of drug use is directly affected by the prescribing behaviour of medical doctors and other healthcare professionals (e.g. nurses, pharmacy technicians, community health workers and health assistants) who sometimes find themselves in the capacity of drug prescribers to patients [26], [27]. Consequently, studying prescribing patterns of medicines in general and antibiotic in particular aids in identifying irrational prescribing behaviors to make therapy more rational and cost effective [28].

Many studies to evaluate rational use of medicines (including antibiotics) in many countries have been reported using the WHO indicators have shown that antibiotic prescription practices vary widely between countries and healthcare facilities [29], [30], [31], [32], [33], [34], [35], [36], [37], [38], [39]. In resource scarce setting where routine empirical antibiotic use, reported either in the form of selfmedication or irrational use in healthcare facilities, is widespread, prescription pattern also varies widely [40].

In Nigeria, several studies on antibiotic prescribing practice has been reported [41], [42], [43]. Studies conducted by [42] and [43] reported that up to $50 \%$ of antibiotic prescriptions may be in the form of empirical prescriptions.
No study on antibiotic prescribing practice in healthcare centres in Nasarawa State, Nigeria has been reported. This study investigates antibiotics prescribing practices in public hospitals in Nasarawa State, Nigeria. The supervision of antimicrobial use has environmental, economic and clinical implications [1].

\section{MATERIALS AND METHODS}

\section{A. Study Area}

The study was conducted in tertiary and secondary healthcare centres in Nasarawa State, Nigeria. The healthcare centres include all general hospitals, specialist hospitals and Federal Medical Centre, Keffi, Nigeria.

\section{B. Study Design and Outcome Variable}

It was a prospective, descriptive and observational study, designed according to the objectives of the study. The outcome indicators are related to prescribing indicators.

\section{Study inclusion/exclusion criteria}

All patients, from both genders and all age groups, which attended secondary and tertiary healthcare centres in Nasarawa State, Nigeria, during the study period from January 2008 to December 2018, were included in our study.

\section{Ethical Approval}

Ethical clearance was obtained from the Ethics and Scientific Review Committee of Nasarawa State Hospital Management Board, Lafia. This was after submission and defence of the Research Protocol and Informed Consent before the Committee.

\section{E. Sampling and Data Collection}

The standard forms provided by WHO were used for data collection. The guidelines and methods were followed to ensure the reliability of all collected data [1]. The data was collected during a period of 10 years from January 2008 to December 2018.

\section{RESULTS AND DISCUSSION}

\section{A. Antibiotic Prescribing Indicators}

The antibiotic prescribing indicators in Nasarawa State during the 10-year period (2008-2018) are given in Table I.

Percentage of hospitalization with one or more antibiotic prescribed was $75.6 \%$. All the hospitals had over $50 \%$ of its patients prescribed 1 or more antibiotic with the highest in General Hospital Obi (98.3\%) and the lowest in General Hospital Akwanga (56.8\%) and Nasarawa Eggon (56.8\%).

Average number of antimicrobials prescribed per hospitalization in which antibiotics were used $( \pm$ SD) was $1.75 \pm 0.66$; with the highest in General Hospital Nasarawa Eggon (2.81 \pm 0.31) and the lowest in General Hospital Keffi $(0.72 \pm 0.12)$.

Average encounter with antimicrobial ( \pm SD) was $0.82 \pm 0.2$; with the highest in General Hospital Awe (1.07 \pm $0.63)$ and the lowest in General Hospital Keana $(0.54 \pm 0.23)$. 
TABLE I: INDICES OF RATIONAL ANTIBIOTIC PRESCRIPTION IN TERTIARY AND SECONDARY HOSPITALS IN NASARAWA STATE, NiGERIA DURING THE PERIOD 2008-2018

\begin{tabular}{|c|c|c|c|c|c|}
\hline $\mathbf{S} / \mathbf{N}$ & Prescribing Indicator & $\begin{array}{c}\text { Value } \\
\text { (Percentage or } \\
\text { Average } \\
\text { Number) }\end{array}$ & $\begin{array}{c}* \text { WHO/INRUD or } \\
\text { **SPS/USAID } \\
\text { Standard }\end{array}$ & $\begin{array}{l}{ }^{\S} \text { African } \\
\text { Standard }\end{array}$ & Remarks \\
\hline 1 & Percentage of hospitalization with one or more antibiotic prescribed & $75.6 \%$ & $20.0-26.8 \%$ & $45.9 \%$ & Fail \\
\hline 2 & $\begin{array}{l}\text { Average number of antimicrobials prescribed per hospitalization in } \\
\text { which antibiotics were used ( } \pm \text { SD) }\end{array}$ & $1.75 \pm 0.66$ & $1.6-1.8$ & - & Pass \\
\hline 3 & Average Encounter with antibiotic $( \pm \mathrm{SD})$ & $0.82 \pm 0.2$ & $\leq 2$ & - & Pass \\
\hline 4 & $\begin{array}{l}\text { Percentage of antimicrobials prescribed consistent with hospital } \\
\text { formulary }\end{array}$ & $100.0 \%$ & $100.0 \%$ & - & Pass \\
\hline 5 & $\begin{array}{l}\text { Average duration of prescribed antimicrobial treatment }( \pm \mathrm{SD}) \text { in } \\
\text { days }\end{array}$ & $5.57 \pm 2.42$ & $7-9$ & - & Pass \\
\hline 6 & Percentage of antimicrobials prescribed by generic name & $45.8 \%$ & $100.0 \%$ & $65.1 \%$ & Fail \\
\hline 7 & Percentage of injectable antibiotic used & $36.4 \%$ & $13.4-24.1 \%$ & $28.4 \%$ & Fail \\
\hline 8 & Percentage antibiotics in an National Essential Medicine List & $85.7 \%$ & $100.0 \%$ & $89.0 \%$ & Fail \\
\hline
\end{tabular}

$*[8],[25],[44]$.

Percentage of antimicrobial prescribed consistent with hospital formulary was $100.0 \%$ in all the hospitals; with $100 \%$ in each of the hospitals.

Average duration of prescribed antimicrobial treatment $( \pm$ SD) was 5.57 \pm 2.42 ; with the highest in General Hospital Obi $(7.42 \pm 0.80)$ and the lowest in General Hospital Nasarawa $(5.1 \pm 2.80)$.

Percentage of antibiotics prescribed by generic name was 45.8\%; with the highest in General Hospital Akwanga $(84.0 \%)$ and the lowest in General Hospital Nasarawa (24.1\%).

Percentage of injectable antibiotic used was $36.4 \%$; with the highest in Federal Medical Centre Keffi (62.8\%) and the lowest in General Hospital Obi (21.2\%).

Percentage of antibiotics used in the essential medicine list was $85.7 \%$. The highest $(100.0 \%)$ was in General Hospital Awe, General Hospital Doma, Dalhatu Araf Specialist Hospital Lafia and Federal Medical Centre Keffi; and the lowest (66.7\%) in General Hospital Nasarawa Eggon, General Hospital Keana and General Hospital Karu.

Inappropriate use of antibiotics is a major cause of antibiotic resistance, treatment failure, increase in the costs of healthcare and an increased occurrence of adverse drug reactions in many countries [31],[45]. Hence, there is the need to adopt measures to promote rational use of medicines. The rational use of drugs is associated with several factors, including health care workers, patients, patient load and health care facilities [31],[46]. Factors that influence rational drug prescription by prescribing health workers include training for rational drugs, years of practice, and educational background [31], [47]. The rational drug prescription is also influenced by the characteristics of health care facilities, including the availability of treatment guidelines and the availability of drugs [31], [46].

This study found that the percentage of hospitalization with one or more antimicrobials prescribed (Indicator 6) was $75.6 \%$. This value is higher than both the WHO (20.0-26.8\%) standard [12] and African (45.9\%) standard. It however, differ from the $72 \%$ from Freetown, Sierra Leone [23], 79\% observed from a tertiary hospital in Eritrea [48], 83\% from Liberia [49], 82.5\% from eastern Ethiopia [50] and 58.1\% from southern Ethiopia [51]. Studies from Nigeria have shown $28 \%$ [52], $42 \%$ [53], 49.2\% [54], 49.5\% [24], 56\% [55] and $94.14 \%$ [27]. This high percentage of antibiotics being prescribed may be due to increased prevalence of infectious diseases in the developing countries necessitating increased amounts of antibiotics being prescribed, high level of routine empirical treatments seen in resource-poor countries, patient pressure on prescribers, self-medication and allowing other healthcare professionals (e.g. health assistants, associate nurses, nurses, health technicians and others) to prescribe [26], [56]. Since this indicator directly measures the extent of antimicrobial use in hospitals, it is safe to conclude that public hospitals in Nasarawa State overuse antimicrobials. Overuse of antibiotics is a common problem in healthcare, which leads to unnecessary expenditure on drugs, raised risk of adverse reactions, and the development of antimicrobial resistance [13].

The observed $1.75 \pm 0.66$ value for average number of antimicrobials prescribed per hospitalization in which antibiotics were used is within the WHO optimal range of 1.6-1.8. While this is commendable for the study area, studies from other parts of Nigeria have shown 1.08 [27] and 1.28 [53]. Our study finding agrees with [57] who reported a value of 1.77; but differs from [39], [58], who reported 1.29, 1.9, 2.0 and 3.5 respectively.

The average encounter with antibiotics observed in this study $(0.82 \pm 0.2)$ was in line with the WHO $(\leq 2)$ standard [12]. Previous study elsewhere described by [58], however reported ted $2.1 \pm 0.3$. The average encounter with antibiotics observed in this study shows that too many antibiotics were not used per prescription.

The Percentage of antibiotic prescribed consistent with hospital formulary was $100.0 \%$, a value same as the WHO (100\%) standard [12]. Deviation from the WHO standard has been reported by [12] who observed 53.6\% in Ghana Police Hospital. Since this indicator measures the degree of prescriber's adherence to the hospital formulary list, the value observed value suggests that the hospitals in the study area adhered to the list of medicines approved by the hospital's Drug and Therapeutics Committee for purchase and prescribing in the hospital. If such a list does not exist, it will 
be necessary to refer to an NEML provided by the ministry of health. Formulary lists represent one way to optimize the use of medicines. Non-adherence to such hospital policy may be caused by prescribers not being aware of or in agreement with the list, listed antimicrobials not being available at the hospital, or prescriptions being listed with brand names while medicines are stocked and dispensed under generic names.

The average duration of antimicrobial treatment observed in this study was $5.57 \pm 2.42$ days, a value lower than the SPS/USAID (7-9 days) standard [25]. Previous studies elsewhere observed 5.4 days [12], 5.65 days and 6.36 days in Eritrea [39]. The optimal duration of therapy for many bacterial infections has not been determined, but the current recommendation is usually 7-10 days of treatment, with longer treatment courses for some diseases, for example, meningitis for 14 days and osteomyelitis for up to six weeks [25]. Since this indicator measures the intensity of patient exposure to antimicrobials during a hospitalization (that is, assesses the length of time antimicrobials are prescribed irrespective of routes of administration or changes in dosage, the observed value from this study indicates insufficient exposure of patients to antimicrobials during treatment. This can provide selective pressure for development of AMR as too short a course of treatment may prolong patient morbidity and promote emergence of drug-resistant organisms [25].

Generic prescribing was found to be $45.8 \%$, a value lower than both the WHO (100\%) standard [12] and African $(65.1 \%)$ standard [44].The observed percentage generic prescribing is lower than $83.14 \%$ in Eritrea by [48], 96\%, $97 \%$ by [48], $98.14 \%$ by [58] and $98.7 \%$ by [51] but higher than $13.18 \%$ reported by [59]. The observed low percentage of generic prescription of antibiotics suggests that the public hospitals in the study area use of unnecessarily expensive drugs when cheaper effective alternatives are available. Other studies elsewhere have reported poor generic prescribing as follows: $13 \%$ in Nepal [59], 30.6\% in Brazil [60], 38\% in Libera [49], 45.2\% in South Africa [61], 57\% in Sierra Leone [23] and 66.8\% in Zaria, Nigeria [24]. Some possible reasons for this non-compliance may include: lack (or poor implementation) of policy on the procurement of antibiotics using generic names, ease of writing of common brand names as opposed to long generic names, high-powered marketing by pharmaceutical sales men, habit, empiric treatment amongst others. Prescribing with generics has notable impact on the rational use of drug with respect to cost, safety and efficacy by permitting the identification of the products by its scientific name [10],[11]. There is thus a need for refresher training for prescribers to conform to the standards in prescribing medicines for patients by generic names.

The percentage of injectable antibiotics used was $36.4 \%$. This value is higher than both the WHO (13.4-24.1\%) standard [12] and the African (28.4\%) standard [11]. The percentage injectable antibiotic observed in this study was higher than $6.3 \%$ by [13], $7.8 \%$ in Eritrea [39], $11.2 \%$ in Ethiopia (Bilal et al., 2016) and 26\% in Sierra Leone [39]; but lower than $38 \%$ by [51] and $67.7 \%$ in Zaria, Nigeria [24]. The high percentage use of injectable antibiotics observed is not appropriate as unnecessary use of injections increases treatment costs, increases risk of infection with blood borne pathogens if needle stick injuries arise and injections need trained health care professional to administer [31]. Prescribers are advised to prescribe non-parenteral routes of administration whenever possible since due to their safety and affordability by patients [62].

The percentage of antibiotics prescribed from the National Essential Medicine List (NEML) was $85.7 \%$, a value lower than both the WHO (100\%) standard [12] and African (89\%) standard [34]. This suggests non-compliance of practices with the Nigerian National Drug Policy on EML. Previous studies have reported $95.5 \%$ in Zaria, Nigeria [24], 95.3\% in Ethiopia [31], $100 \%$ in Abuja, Nigeria [27] and $100 \%$ in Eritrea [39], 32.8\% in Nepal [59], 63.9\% in Sierra Leone [34], $67.7 \%$ in Western China [63]. Possible reasons for deviation from WHO standard include: non-availability of the EML at the hospitals for the prescribers to get acquainted with; nonavailability of such antibiotics from the drug store; and failure to strictly implement the Nigerian National Drug Policy on prescribing from the essential medicine list. Essential medicines lists promote the use of a minimum number of selected medicines with the intention of ensuring their more rational use at the least possible cost to the health system and consumers. Therefore, it is not sufficient to develop a NEML, it is more crucial to ensure its acceptance and use by the prescribers.

\section{CONCLUSION}

Our study revealed that some antibiotic prescribing indicators in the public hospitals in Nasarawa State, Nigeria, deviate from WHO standard for rational prescribing while others complied with it. Compliance was observed in respect of: average number of antimicrobials prescribed per hospitalization in which antibiotics were used, average patient encounter with antibiotic and percentage of antimicrobials prescribed consistent with hospital formulary. Non-compliance was observed in respect of: percentage of hospitalization with one or more antibiotic prescribed, average duration of prescribed antimicrobial treatment, percentage of antimicrobials prescribed by generic name, percentage of injectable antibiotic used and percentage of antimicrobials on National Essential Medicine List. Concrete steps should be taken to: reduce overuse of antibiotic use, increase antimicrobial treatment period, improve generic prescribing, reduce use of injectable dosage forms and improve adherence of prescribers to the National Essential Medicine List (NEML). To achieve all these, training and extensive continuing education programmes targeting prescribers; and regular updating and wide dissemination of National Standard Treatment Guideline should be promoted.

\section{ACKNOWLEDGMENT}

This research was funded by the "Institution-Based Research grant 2013-2015 (merged)', awarded to Professor Y.B. Ngwai $\mathrm{PhD}$ and Dr. I.H. Nkene PhD by Tertiary Education Trust Fund (TETFund), Abuja, Nigeria. 


\section{CONFLICTS OF INTEREST}

The authors declare no conflicts of interest regarding the publication of this paper.

\section{REFERENCES}

[1] WHO, the pursuit of responsible use of medicines: sharing and learning from country experiences? Vet Rec. 169:78 2012.

[2] CDC, Centers for Disease Control and Prevention. Therapeutic drug use. Accessed 09 Dec 2013

[3] WHO, how to investigate drug use in health facilities? Selected drug use indicators. Action programme on essential drugs. World Health Organization, Geneva, 1993, pp. 1- 87.

[4] N. Antonakis, I. Xylouri, M. Alexandrakis, C. Cavoura, C. Lionis, Seeking prescribing pattern in rural Crete: a pharmacoepidemilogical study from a primary care area. (online). Int. Electron. J. Rural. Remote Health, 2006, 6 (488): 1-10.

[5] WHO, Medicines: rational use of medicines? Available at http://www.who.int/medicines/areas/ rational use/en/. 2014.

[6] WHO, The rational use of drugs? Report of the Conference of Experts Geneva, 1985.

[7] WHO, Policy perspectives on medicines: Promoting rational use for medicines: core components 2002

[8] M. Atif, M. R. Sarwar, M. Azeem, D. Umer, A. Rauf, A. Rasool, M Ahsan, S. Scahill, Assessment of WHO/INRUD core drug use indicators in two tertiary care hospitals of Bahawalpur, Punjab, Pakistan. J Pharm Policy Pract. 2016a, 9(1):27.

[9] G. S. Bbosa, G. Wong, D. B. Kyegombe, J. Ogwal-Okeng, Effects of intervention measures on irrational antibiotics/antibacterial drug use in developing countries: a systematic review. Health, 2014, 6: 171187.

[10] M. B. C. Ferreira, I. Heineck, L. M. Flores, A. L. Camargo, T. D. S Dal Pizzol, I. L. D. S. Torres, et al. Rational use of medicines: prescribing indicators at different levels of health care. Braz J Pharm Sci. 2013; 49:329-40.

11] A. K. Wagner, J. D. Quick, D. Ross-Degnan, Quality use of medicines within universal health coverage: challenges and opportunities. BMC Health Serv Res. 2014; 14:357.

[12] K. D. Tripathi, Essentials of Medical Pharmacology, 6 e(d) New Delhi: Jaypee Brothers Medical Publishers (P) Ltd 2008, pp. 667

13] D. K. Yimenu, A. Emam, E. Elemineh, W. Atalay, Assessment of Antibiotic Prescribing Patterns at Outpatient Pharmacy Using World Health Organization Prescribing Indicators. Journal of Primary Care \& Community Health, 2019, Volume 10: 1-8.

[14] WHO, Global Strategy for Containment of Antimicrobial Resistance 2001, Accessed 29 Jun 2013.

[15] M. A. Woldu, S. Suleman, N. Workneh, and N. Berhane, Retrospective Study of the Pattern of Antibiotic Use in Hawassa University Referral Hospital Pediatric Ward, Southern Ethiopia.Journal of Applied Pharmaceutical Science, 2013, 3 (02):093-098.

[16] C. R. Lee, J. H. Lee, L. W. Kang, B. C. Jeong, and S. H. Lee, "Educational effectiveness, target, and content for prudent antibiotic use," BioMed Research International, 2015, 13:2015.

[17] C. E. Nwolisa, E. U. Erinaugha, S. I. Ofoleta, Prescribing practices of doctors attending to under-fives in a children's outpatient clinic in Owerri, Nigeria. J Trop Pediatr 2005; 52:197-200.

[18] K. A. Oshikoya, H. A. Chukwura, O. I. Ojo, Evaluation of outpatient paediatric drug prescriptions in a teaching hospital in Nigeria for rational prescribing. Paediatr Perinat Drug Ther 2006; 7:183-8.

[19] M. Atif, M. Azeem, M. R. Sarwar, S. Shahid, S. Javaid, H. Ikram, et al. WHO/INRUD prescribing indicators and prescribing trends of antibiotics in the accident and emergency department of Bahawa Victoria hospital, Pakistan. Springerplus, 2016b, 5:1928.

[20] C. P. Cole, P. B. James, A. T. Kargbo, An evaluation of the prescribing patterns for under-five patients at a tertiary paediatric hospital in Sierra Leone. J Basic Clin Pharma 2015; 6:109-14.

[21] S. N. Deshmukh, M. M. Mahajan, A study of prescription pattern of antibiotics in paediatric in-patients at a tertiary care hospital in central India. Int J Pharm Res 2016; 6:286-90.

[22] S. O. Nduka, C. Edebeatu, C. P. Isidienu, K. C. Amorha, Prescribing practices for pediatric out-patients: A case study of two teaching hospitals in Nigeria. Trop J Pharm Res 2017; 16:705-11.

[23] Cole CP, Philip Routledge P (2018). An evaluation of rational prescribing in hospital outpatient practice in Sierra Leone and assessment of affordability of a prescription as an outcome. Pan African Medical Journal. 2018; 31:174.
[24] L. W. Umar, A. Isah, S. Musa, B. Umar, Prescribing pattern and antibiotic use for hospitalized children in a Northern Nigerian Teaching Hospital. AnnualAfrical Medicine, 2018, 17(1):26-32.

[25] SPS/USAID, How to Investigate Antimicrobial Use in Hospitals: Selected Indicators. Strengthening Pharmaceutical Systems. Published by the Strengthening Pharmaceutical Systems Program. Arlington, VA: Management Sciences for Health; supported by the U.S. Agency for International Development (USAID) 2012.

[26] C. P. Babalola, S. A. Awoleye, J. O. Akinyemi, O. A. Kotila Evaluation of prescription pattern in Osun State (Southwest) Nigeria Journal of Public Health and Epidemiology, 2011, 3(3): 94-98.

[27] M. I. Aboh, E. W. Tosin, O. C. Daniels, P. Oladosu, M. Emeje, Rational Use and Prescribing Pattern of Atibiotics in Abuja, Nigeria. Journal of Phytomedicine and Therapeutics (JOPAT), 2018; 17(2): $180-188$.

[28] R. P. Shankar, P. Partha, N. K. Shenoy, J. M. Easow, K. N Brahmadathan, Prescribing patterns of antibiotics and sensitivity patterns of common microorganisms in the internal medicine ward of a teaching hospital in Western Nepal: a prospective study. Ann Clin Microbiol Antimicrob. 2003;2(1):7.

[29] S. Otoom, A. Batieha, H. Hadidi, M. Hasan, K. Al-Saudi, Evaluation of drug use in Jordan using WHO prescribing indicators; 2002.

[30] K. Bashrahil, Indicators of rational drug use and health services in Hadramout, Yemen; 2010.

[31] A. T. Vooss, H. S. Diefenthaeler, Evaluation of prescription indicators established by the WHO in Getúlio Vargas-RS. Braz J Pharm Sci. 2011;47(2):385-90

[32] A. El-Mahalli, WHO/INRUD drug prescribing indicators at primary health care centres in eastern province, Saudi Arabia; 2012.

[33] S. Hashemi, A. Nasrollah, M. Rajabi, Irrational antibiotic prescribing a local issue or global concern? EXCLI J. 2013; 12:384

[34] K. D. Gidebo, T. S. Summoro, Z. Z. Kanche, E. W. Woticha, Assessment of drug use patterns in terms of the WHO patient-care and facility indicators at four hospitals in southern Ethiopia: a crosssectional study. BMC Health Serv Res. 2016;16(1):643.

[35] R. Andrajati, A. Tilaqza, S. Supardic, Factors related to rationa antibiotic prescriptions in community health centers in Depok City, Indonesia. Journal of Infection and Public Health, 2017, 10: 41-48.

[36] A. Aravamuthan, M. Arputhavanan, K. Subramaniam, Assessment of current prescribing practices using World Health Organization core drug use and complementary indicators in selected rural community pharmacies in southern India. J Pharm Policy Pract, 2017;10(1):1.

[37] A. T. Barghouthi, and M. Mensa, Retrospective drug use pattern of antibiotics in pediatric ward of Shenan gibe hospital, Oromia region, Ethiopia. J Antibio Res. 2017;1(1):106.

[38] M. Sisay, G. Mengistu, B. Molla, F. Amare, T. Gabriel, Evaluation of rational drug use based on World Health Organization core drug use indicators in selected public hospitals of eastern Ethiopia: a cross sectional study. BMC Health Serv Res. 2017;17(1):161.

[39] N. D. Amaha, D. G. Weldemariam, N. Abdu, E. H. Tesfamariam, Prescribing practices using WHO prescribing indicators and factors associated with antibiotic prescribing in six community pharmacies in Asmara, Eritrea: a cross-sectional study. Antimicrobial Resistance and Infection Control, 2019, 8:163.

[40] U. I. Eshiet, G. S. Effiong, and A. E. Akwaowoh, The use of antibiotics in a Nigerian tertiary healthcare facility. American Journa of Biomedical Science and Engineering, 2015, 1(3):25-31.

[41] S. N. Abdu-Aguye, A. Haruna, A. Shehu, and K. S. Labaran, An assessment of antimicrobial prescribing at a tertiary hospital in North western Nigeria. African Journal Pharmacology and Therapy, 2016 5(4):229-234

[42] O. O. Oduyebo, A. T. Olayinka, K. C. Iregbu, A. Verspoten, H. Goosens, P. I. NwajiobiPrincewill, O. Jimoh, T. O. Ige, A. I. Aigbe, O. I. Ola-Bello, A. O. Aboderin, F. T. Ogunsola, A point prevalence survey of antimicrobial prescribing in four tertiary hospitals.Annual Tropical Pathology, 2017, 8:42-46.

[43] O.O. Paul, and A. Abdulmalik, Empirical Antibiotic Prescription Pattern among Patients in a Nigerian Tertiary Hospital, is There Evidence of Irrationality? Journal of Advances in Medicine and Medical Research, 2019, 30(6): 1-11.

[44] R. Ofori-Asenso, P. Brhlikova, A. M. Pollock, Prescribing indicators at primary health care centers within the WHO African region: a systematic analysis (1995-2015). BMC Public Health. 2016, $16(1): 724$

[45] N. E. Bilal, M. Gedebou, and S. Al-Ghamdi, Endemic nosocomial infections and misuse of antibiotics in a maternity hospital in Saudi Arabia. Acta PathologicaMicrobiologica ImmunologicaScandinavica, 2002, 110 (2):140-147. 
[46] N. F. Basaran, F. Akici, Aspects of physicians' attitude towardsthe rational use of drugs at a training and research hospital:a survey study. Eur J Clin Pharmacol, 2013, 69:1581-1587.

[47] NIHRD, National Institute of Health Research and Development Ministry of Health Republic of Indonesia. 2013 Indonesia basic health research; 2013. p. 66-74.

[48] N. D. Amaha, Y. H. Berhe, A. Kaushik, Assessment of inpatient antibiotic use in Halibet National Referral Hospital using WHO indicators: a retrospective study. BMC Res Notes. 2018;11(1):904.

[49] J. Harris, Assessing the rational use of essential medicines in public health facilities Mont-serrado County, Liberia. (MSc Pharmaceutical Management) 2012. Tanzania: Muhimbili University.

[50] A. I. Bilal, E. D. Osman, A. Mulugeta, Assessment of medicines use pattern using World Health Organization's prescribing, patient care and health facility indicators in selected health facilities in eastern Ethiopia. BMC Health Serv Res. 2016;16(1):144.

[51] A. A. Desalegn, Assessment of drug use pattern using WHO prescribing indicators at Hawassa University teaching and referral hospital, South Ethiopia: a cross-sectional study. BMC Health Serv Res. 2013;13(1):170.

[52] E. T. Adebayo, N. A. Hussain, Pattern of prescription drug use in Nigerian army hospitals. Ann Afr Med. 2010; 9(3): 152-158. Google Scholar.

[53] A. A. Mgbahurike, I. Idowu, C. I. Igwilo, Antibiotic Utilization and Prescribing Patterns in a Nigerian University Medical Center. Nigerian Journal of Pharmaceutical Research, 2010, 8 (1): 236 - 241.

[54] A. Joda, R. Aderemi-Williams, A comparative study of prescribing patterns in two tertiary care teaching hospitals in Lagos, Nigeria. International Journal of Pharmacy and Pharmacology. 2013; 2(1): 041-046.Google Scholar.

[55] P. Erah, G. Olumide, A. Okhamafe, Prescribing practices in two health care facilities in Warri, Southern Nigeria: a comparative study. Tropical Journal of Pharmaceutical Research. June 2003; 2(1): 175182.Google Scholar

[56] Y. Ateshim, B. Bereket, F. Major, Y. Emun, B. Woldai, I. Pasha, E. Habte, M. Russom. Prevalence of self-medication with antibiotics and associated factors in the community of Asmara, Eritrea: a descriptive cross-sectional survey. BMC Public Health. 2019;19(1):726.

[57] J. Prah, J. Kizzie-Kayford, E. Walker, A. Ampofo-Asiama, Antibiotic prescription pattern in a Ghanian healthcare facility. Pan Africal Medical Journal, 2017, 28:214.

[58] F. Worku, D. Tewahido, Retrospective assessment of antibiotics prescribing at public primary healthcare facilities in Addis Ababa, Ethiopia. InterdiscipPerspect Infect Dis. 2018:43:23769.

[59] S. Ghimire, S. Nepal, S. Bhandari, P. Nepal, S. Palaian, A prospective surveillance of drug pre-scribing and dispensing in a teaching hospital in western Nepal. J Pak Med Assoc. 2009 Oct; 59(10): 72631.PubMed.

[60] S. V. Dos, S. Ottati, O. Nitrini. Prescription and patient-care indicators in healthcare services. Rev SaúdePública. 2004; 38(6): 819-26. PubMed | Google Scholar.

[61] G. Mohlala, K. Peltzer, N. Phaswana-Mafuya, S. Ramlagan, Drug prescription habits in public and private health facilities in 2 provinces in South Africa. EMHJ. 2010; 16(3): 324-8. PubMed | Google Scholar.

[62] W. F. Fikru, and T. D. DagmawitTewahido, Retrospective Assessment of Antibiotics Prescribing at Public Primary Healthcare Facilities in Addis Ababa, Ethiopia. Interdisciplinary Perspectives on Infectious Diseases, 2018:1-9.

[63] L. Dong, H. Yan, Wang D. Drug prescribing indicators across village health clinics across 10 provinces of Western China. Fam Pract. 2011 Feb; 28(1): 63-7. PubMed | Google. 